\title{
Using Grounded Theory Method in Information Systems: The researcher as blank slate and other myths
}

\author{
Cathy Urquhart ${ }^{1}$, Walter Fernández ${ }^{2}$
}

\author{
${ }^{1}$ Manchester Metropolitan University Business School, Manchester Metropolitan University, Manchester, UK; \\ ${ }^{2}$ Research School of Accounting \& Business Information Systems, Australian National University, Canberra, \\ Australia

\section{Correspondence:} \\ C Urquhart, Marketing, Operations and Digital Business, Manchester Metropolitan University Business School, \\ Manchester Metropolitan University, Manchester M15 6BH, United Kingdom \\ E-mail: c.urquhart@mmu.ac.uk
}

Note: the authors contributed equally to the paper.

Keywords: Grounded Theory, Research Methods, Qualitative Research

\section{Abstract}

The use of grounded theory method (GTM) as a research method in information systems has gradually increased over the years as qualitative research in general has become more prevalent. The method offers a systematic way to generate theory from data, but is rarely used to its full potential in information systems as a number of myths and misunderstandings about GTM prevent researchers from getting the full potential out of the method. To address this problem, we advance the general level of knowledge of GTM. We clarify aspects of the method that are often misunderstood by novice users or casual observers and provide guidance to address common problems. Exemplars from the information systems literature are used to illustrate the concepts and to promote the informed use of the methodology. By doing so, this paper will contribute to improving the use of the method and to the quality and dissemination of grounded theory research outcomes. 


\section{Introduction}

Grounded theory method (GTM) was developed in the field of sociology during the 1960s (Glaser and Strauss, 1967) and has been adopted in many fields of research, including information systems (IS). The use of GTM in IS studies echoes the progress of interpretive research from insignificance in the 1980s (Orlikowski and Baroudi, 1991) to its current mainstream status in the IS community (Klein and Myers, 2001, Markus, 1997). Grounded theory research has been published in the major journals of IS and the methodology has gained enough support to have its own special interest group within the Association of Information Systems.

While the adoption of GTM is increasing, it is also true that as late adopters of the method IS researchers confront a number of issues surrounding this methodology. A recurrent issue is the mislabelling of studies as GTM (e.g., Jones and Noble, 2007, Suddaby, 2006, Urquhart and Fernandez, 2006). Mislabelling, at best, suggests a level of ignorance; and at worst, a possible lack of integrity when the GTM label is used as a legitimising jargon, without a deep understanding of fundamental concepts (Glaser, 2009). For example, using the label "GTM" as a generic term to categorise qualitative studies where anything goes so long the study is claimed to be grounded in empirical data (Jones and Noble, 2007). In addition, Urquhart and Fernández (2006) described concerns with myths regarding the nature of GTM and how these negatively influence the adoption and the use of GTM in IS research (see also Suddaby, 2006).

Therefore, there is significant value in addressing the case of mislabelling of GTM arising from the perspective of misinterpretations, rather than misrepresentations. This is so because misinterpretations are often the product of unreflective methodological knowledge, which can be addressed by scholarly discussion. In this article we extend our previous work (Urquhart and Fernandez, 2006) by addressing the issue of misconceptions and myths from the perspective of the expert grounded theorist. Hence, the objective of this paper is to advance the discussion and treatment of unfounded, yet common, myths or beliefs that delay the diffusion of GTM as it was intended - a rigorous methodology that facilitates high-quality theory development. To that end, this paper lists major misconceptions, provides ways of addressing potential shortcomings and suggests practical approaches to address common problems. The rest of this article is structured as follows. First we briefly describe the nature of GTM. Second, we discuss how grounded theory has been applied in IS to date. Third, we identify some prevalent misconceptions about GTM in the IS community. Fourthly, we then offer some flexible guidelines to help to help maximise the quality of grounded theory studies, and thus their potential for publication. Before concluding, we discuss the status of GTM in IS as an essentially contested concept (Gallie, 1956).

\section{The Grounded Theory Method}

The grounded theory method originated in the social sciences, with the aim of generating empirically grounded theory (Glaser and Strauss, 1967) based on the systematic exploration of a phenomenon. The method aims "to discover what is going on, rather than assuming what should go on" (Glaser, 1978 p.159). In this context, the "discovery" relates to the identification of useful theoretical conceptualisations based on a rigorous, systematic and comprehensive approach to data collection and analysis (Fernandez and Lehmann, 2005).

The method, adopted in sociology and nursing during the 1970s, took more than two decades to be used in IS. Scholars in the IFIP Working Group 8.2 Conference Proceedings presented the first papers using GTM in IS research: Toraskar (1991) and Calloway and Ariav (1991). Two year later Orlikowski's seminal (1993) paper on CASE use in organisations, significantly contributed to the legitimacy of grounded theory as a method in IS. Orlikowski (1993) justified her use of GTM on three counts: it was useful for areas where no previous theory existed, it incorporated the complexities of the organisational context into the understanding of the phenomena, and the method was uniquely fitted to studying process and change. 
Thus, GTM provides an attractive research approach to IS researchers interested in issues of process and context: key concerns when studying new organisational phenomena (Van de Ven and Poole, 1989). By conducting research in its social and historical context, researchers are able to obtain a good appreciation of the work of people as active builders of their own physical and social reality (Orlikowski and Baroudi, 1991). Further, the close study of actors, their actions and their context facilitates the production of meticulous substantive theory (a theory developed for a particular empirical area of enquiry) that can then be integrated with existing theory (Orlikowski, 1993).

In GTM, concepts are developed through constant comparison. This is the process of constantly comparing instances of data in a particular category against other instances of data, to see if these categories fit and are workable. Constant comparison is the driving technique of GTM's data analysis, the facilitator of theoretical sampling, and thus the means to reach what Strauss and Glaser (1967) call theoretical saturation; the point at which data gathering stops and the substantive grounded theory begins to emerge. Theoretical sampling requires the collection of slices of data of varied nature, seeking both converging and diverging evidence. Theoretical sampling provides researchers with limitless options for data gathering, including different collection techniques and data types - for example, observations, interviews, historical records and surveys. The aim of theoretical sampling is to generate "different views or vantage points from which to understand a category and to develop its properties" (Glaser and Strauss 1967, p.65). Theoretical sampling enables the researcher to sample along an emergent storyline, deciding on analytic grounds where to sample from next.

We should also emphasise that while following the GTM coding procedures are necessary, slavish adherence to those procedures is not on its own sufficient to produce good theoretical outcomes. It is possible to follow the mechanics of method and yet fail to contribute with valuable conceptualisations (Suddaby, 2006, Urquhart et al., 2010, Urquhart et al., 2009). As Klein and Myers (1999) warned with regard to their principles for interpretive field studies in IS, the analytical guidelines offered by GTM cannot be applied mechanistically; rather, the grounded theorist has to use considerable judgment to determine their applicability, pacing and relevance. Furthermore, by following the coding rules, without a deeper understanding of the method, it is possible to end up with raw data that has been mechanically elevated to a substantive theory without interpreting what is happening at each stage of coding (Suddaby, 2006).

The key purpose of grounded theory research is to propose theories that are primarily and strongly connected to data collected in a substantive field (Glaser and Strauss, 1967). However, the application of grounded theory in IS has ranged from its use purely as a qualitative data analysis method producing context-bounded descriptions, through to its use to generate full blown theory(Urquhart et al., 2010). Yet, the remodelling of GTM into a tool for qualitative descriptions (Glaser, 2001) is not unique to IS as other disciplines have noted that GTM is often used for purposes other than generating theory (Becker, 1993, Benoliel, 1996, Elliott and Lazenbatt, 2005, Green, 1998).

Although GTM guidelines can enable researchers to derive theory that is empirically valid (Eisenhardt, 1989, Glaser and Strauss, 1967, Martin and Turner, 1986), these guidelines are designed to allow for flexibility (Charmaz, 2006); this underlines the need to have a good comprehension of the overall method, its demands and its possibilities.

Like all sophisticated research approaches, GTM requires a degree of careful training to master. Researchers new to GTM can benefit from substantial training in conducting empirical fieldwork, and from expert guidance in all stages of analysis, including how to integrate the extant literature during the different phases of the study. If these aspects of GTM are not sufficiently mastered, it is likely to fail in the same way that simply running a bunch of numbers that one picks up from various sources through statistical analysis software can fail the under-trained quantitative analyst.

To better understand GTM misconceptions, in the next two sections we use examples from articles showing a high "degree of conceptualisation and theory scope" (a criterion proposed by Urquhart et al., 2010) found in the top two IS journals, Information Systems Research and MIS Quarterly. We 
selected these journals for practical reasons: they provide sufficient evidence to illustrate our discussion without turning the article into a literature review. However, we strongly advise to read the excellent body of GTM work published at outlets such as Journal of Information Technology, European Journal of Information Systems, Information Technology \& People, Journal of the Association of Information Systems, Information \& Management, and Information Systems Journal.

In addition, it is important to note the proceedings of IFIP 8.2 Conferences, whose scholars played a pioneering role in the diffusion of GTM in IS as well as the strong tradition of grounded theory articles in the European Journal of Information Systems, dating from the early 1990's. For an early example of theory building using Strauss and Corbin, for instance, we recommend Galal (2001). For an early example of innovative adaptations of grounded theory in IS, see Lings and Lundell (2005).

\section{Addressing Key Misconceptions}

This section discusses the most common misconceptions about GTM that need to be addressed. There is a deceptive simplicity to a number of key misconceptions about GTM, which, in our view, act as a significant obstacle to leveraging the theory building potential of GTM in IS research.

\section{Misconception 1-The Researcher as a Blank Slate}

The premise that the grounded theory researcher is a 'blank slate', who launches into data collection without first looking at the literature, is a particularly pervasive misconception (Andrew, 2006, McCallin, 2003). This misconception about GTM is possibly most harmful, because understanding the role of the literature in GTM is essential to producing good grounded theories. Also, one reviewer noted: "[b]lank slater thinking seems to mean the grounded theorist is to forget what they know in order to learn what they need. This naïve articulation is one of the most pernicious symptoms of ignorance regarding the demands that grounded theory approaches place on the scholar."

The origin of this misconception can be attributed to a misinterpretation of one of the basic tenets of grounded theory: the researcher must set aside the extant theory. Yet, this tenet does not imply GTM researchers must ignore the existing literature and become a tabula rasa.

The idea of the researcher as a blank slate has at its base a superficial reading of the literature. Glaser and Strauss (1967 p.33) warned researchers against the extant literature dictating "prior to the research, 'relevancies' in concepts and hypothesis." However, construing this warning as a dictum requiring a blank mind is either a misrepresentation or a misinterpretation. The very crux of GTM is the rigorous generation of theory using systematic procedures, analytical skills and theoretical sensitivity, which emanate from knowledge of the extant literature. We must also emphasise that all the key texts of GTM stress the need to engage the resultant theory with the literature; these texts also explain how this integration should be done (including Glaser, 1978, Glaser, 1998, Glaser and Strauss, 1967, Strauss, 1987, Strauss and Corbin, 1990).

In GTM, known theories are set aside for potential future comparison, which are done only if the analysis of the data indicates the relevance of these theories. This is the manner in which the GTM researcher enables the emergence of patterns from the empirical data, and also the way in which extant theory is integrated into the study. Setting aside implies that the theorist understands the role of both knowledge and detachment to a grounded study. Theoretical and practical knowledge can enhance the theoretical sensitivity of researchers while their ability to detach from the acquired knowledge is critical to set aside preconceptions and look the data anew (Charmaz, 2006). This skill allows researchers to access existing knowledge of theory without being trapped in the view that it represents the final truth (as also suggested by Walsham, 1995).

Thus, grounded theory offers a way to deal with pre-existing knowledge bias and a way of integrating this knowledge with empirical data. This is necessary because "[e]ach of us brings to the analysis our own biases, assumption, patterns of thinking, and knowledge gained from experience and reading"(Strauss and Corbin, 1990 p.95). At times, this may require delaying readings on the 
substantive area of research that might "stifle or contaminate or otherwise impede the researcher's effort to generate categories" (Glaser, 1992 p.31).

Related to bias and contamination is the researcher's level of maturity. Strauss (1987) explains that the recommendation to delay the scrutiny of related literature applies less to experienced researchers, as they are more practiced at subjecting theoretical statements to comparative analysis - that is, testing and contrasting empirical data against the researcher's biases, assumptions and knowledge. GTM considers the researcher's knowledge, experiential and theoretical, as critical to achieving the required level of theoretical sensitivity and thus to enabling theoretical memoing, constant comparison and theoretical integration (Glaser, 1992).

In Section 4 of this paper we will provide some guidelines for engaging with the literature in a GTM study, and for integration of the literature at write up stage.

\section{Misconception 2-GTM is Inflexible}

Because of its complex nature and conflicting guidance about how to apply the method, GTM is sometimes seen as inflexible and difficult to apply. One reason for the conflicting guidance is the well documented split between Glaser and Strauss in 1990, on the publication of Basics of Qualitative Research by Strauss and Corbin. Glaser objected to Strauss and Corbin's coding paradigm which was at the centre of their book. The coding paradigm suggested that the researcher looks for context, conditions, action/interactional strategies, intervening conditions and consequences as a guide to grouping and establishing relationships between codes, and seemed to be mandatory. Glaser (1992) objected to the coding paradigm and to the line-by-line coding proposed by Strauss and Corbin (1990). Glaser argued that the way of doing research presented by Strauss and Corbin was no longer grounded theory due to the forcing effect of the coding paradigm. The often quoted statement "If you torture the data long enough, it will give up! " (p.123) represents the most condensed version of Glaser's appreciation of the Straussian approach, as it was to be called, to differentiate it from the Glaserian approach (Stern, 1994). Glaser also asserted that "forcing by preconception constantly derails it [the research] from relevance" (Glaser, 1992 p.123).

However restrictive it may be perceived by some grounded theorists, the Strauss and Corbin approach to GTM was a publishing success. The book was effectively promoted and distributed by a major publishing company; since then it has been widely available and adopted.

In contrast, Glaser published his books using a small publishing company, Sociology Press, which he founded in 1970 to preserve the integrity of the method while contributing to its development. ${ }^{i}$ The narrow focus of the publishing company and its more modest operation restricted the diffusion of what Glaser calls classic grounded theory. Classic grounded theory scholars mainly congregate around Sociology Press, the Grounded Theory Institute and the Grounded Theory Review journal; all these entities were either created or facilitated by Glaser. Thus, the diffusion of classic GTM to a great extent depends on these scholars and their "word-of-mouth" promotions.

Each strand has its adherents. This split among GTM researchers can be partially attributed to fuelling the debate about the very nature of grounded theory. The Glaserian approach suits researchers seeking flexibility. The Straussian approach suits those seeking a more prescriptive method. It should also be noted that the dispute has an interesting codicil: after eighteen years, the coding paradigm is all but abandoned in Corbin and Strauss (2008), where it is no longer mandatory, and is simply represented as one of many possible analytical tools.

The conflicting advice on approaches also leads some people to think that GTM is difficult, and perhaps risky for PhD students, as they may find themselves in the firing line of competing approaches, each with passionate supporters. An example of this kind of thinking can be seen in a recent blog (Myo, 2012). This contrasts markedly with our own positive experiences, and that of our students, in using GTM. In our view, it is simply a case that one needs to be aware of the intellectual 
history of GTM, as opposed to being worried by that history. We will return to this issue of positioning in our guidelines section.

Moreover, the notion that GTM is inflexible is not borne out when one considers its widespread use. Furthermore, while the Straussian approach can be perceived as less flexible, and with a higher risk of forcing preconceptions, evidence from IS literature depicts a more positive outlook (see Table 2 in Appendix). Based on this evidence, we cannot conclude that GTM is inherently inflexible, in any of its forms, at least when it is used by expert researchers. In other words, the reasons for the debate between the espoused views on GTM are not corroborated in practice at the top level of information system publishing.

In IS, as Table 2 shows, GTM has been used in accordance with different research needs and epistemological positions; it has been applied as the sole method and in combination with others; it has produced new theories; and it has been used to show the relevance of extant theories from other fields to IS research. While each article in Table 2 presents important aspects of the method and how it can be used, one example, Ransbotham and Mitra (2009), is particularly interesting, as it shows how theory generation and testing can be (a) conducted sequentially to generate theory and then test the generated theory; and (b) also effectively reported in a single article. This exemplar is likely to inspire those inclined to pursue multi-paradigm research.

\section{Misconception 3-GTM Produces Low Level Theories which don't do much}

This issue has its foundation in the view that GTM's concern with a limited substantive field prevents the development of theories with greater appeal in terms of usability or generalisability. Some scholars indicate the need to break away from focusing on micro phenomena as this prevents the grounded theorist from enriching the research by considering macro structures (Layder, 1993, cited in Walsham, 1995). In fact, the method encourages the production of theories that have explanatory and predictive powers beyond the substantive fields from which the theory emerged, as detailed in the original book (Glaser and Strauss, 1967). Below, we discuss reasons for low level theoretical outcomes, ways to avoid common traps that could derail the achievement of valuable theoretical results.

One of the potential causes for low level theory can be seen as a consequence of the type of "bottom up' coding, which GTM employs. As Charmaz (2006) points out, the logic of 'discovery' in the GTM coding process enables researchers to look at the data anew and to produce rich theory, closely linked to the data. Indeed, this is a major strength of GTM. Closeness to empirical data is necessary to produce substantive grounded theory. However, one must not stop reading at this point. Closeness to data is a necessary but not sufficient condition to achieve a valuable theoretical outcome. The GTM literature acknowledged from its beginning that substantive theory development can shade into formal theories (Glaser, 1978, Glaser, 2007, Glaser and Strauss, 1965, Glaser and Strauss, 1967, Strauss, 1987, Strauss and Corbin, 1990). Yet, the early definitions of substantive and formal theory were unclear (Alvesson and Sköldberg, 2000) and this lack of precision caused confusion and misinterpretations (Glaser, 2007).

Indeed, GTM places an obligation on the researcher to keep working on theory development until what in grounded theory parlance what is called formal theory is achieved (Glaser, 2007, Strauss, 1987) ${ }^{\mathrm{ii}}$. The Straussian strand of grounded theory further considers the problem of scaling up by virtue of the conditional matrix (Strauss and Corbin, 1990 p.161), which allows the integration of more 'macro' issues into the resulting theory. The conditional matrix considers conditions and consequences in a set of concentric circles, which represent successive layers of context - groups, sub organisational, institutional level, organisations and institutions, community, national, and international.

While substantive theories can provide suitable explanation of a phenomena in a particular setting, formal grounded theories can transcend the areas from which the initial substantive theory emerged, 
becoming more general in explaining the core variable that emerged from the substantive theory. This is more useful in predicting or anticipating outcomes. The level of 'formality' refers to how well the theory (a) focuses only on general categories and hypotheses, (b) presents conceptualisations are highly generalisable for practical application across a number of contexts, and (c) has been developed to generalise a core category emergent from a substantive grounded theory (Glaser, 2007). An early example of a formal theory is social value of people which was partially derived from the substantive theory of social loss of dying patients. In both of these cases, the social loss or social value are calculated on the basis of apparent and learned characteristics of the person; however, the formal theory requires comparative analysis across different substantive groups (Glaser and Strauss 1967).

Both substantive and formal grounded theories are expected to produce good research outcomes when the research is well planned and executed. Yet, the low level of theoretical outcomes in some studies often indicates a partial understanding (or a partial application) of the methodology-for example, studies that follow GTM techniques only to the extent that they produce rich descriptions based on coding, categorisation and sorting of data without due regard to conceptualisation (Suddaby, 2006). When the coding activity produces description rather than abstract conceptualisations, studies run the risk of not being scalable to theory, and thus remaining tied to the details of the substantive field without being able to achieve the desired theoretical outcome (Glaser, 2001). Reflecting on this bias for description, Glaser (2001 p.94) stated "I am always amazed, given the pressure to generalize, the ease of doing it with GT, and the fact that all substantive GTs have general implications, at how many GT researchers do not develop or even mention the generalization of their basic social process or core variable, or sub-core categories."

The partial application of GTM often occurs when studies are concluded before theoretical coding (establishing relationships between concepts) has been done. In these cases, researchers are likely to produce theories that are low in value: neither well-presented nor well integrated with the relevant literature. Grounded theorists have the necessary freedom to apply a theoretical lens that fits the data, whatever that theoretical lens is, so long as the lens fits and is not forced on the data. This is particularly so in the case in classic grounded theory, but since Corbin's departure from demanding a particular coding paradigm (Corbin and Strauss, 2008) it applies to both Straussian and Glaserian approaches. Glaser (1978) suggests several routes to extending and scaling up the theory, including considering how the substantive theory relates to formal models and processes. To this end, researchers could opt to use theoretical codes, to assist in the relating of categories. Theoretical codes are useful extant theories that offer the potential to make the substantive codes relevant and understandable, integrating the substantive codes and relating them in new patterns (Glaser, 1978).

As the number of theoretical codes is ever-growing, the ability to see and to apply theoretical codes depends only on the researcher's theoretical sensitivity. That is, their awareness of extant formal theories from a range of fields (Glaser, 2005). This sensitivity is gained over time via constant interaction between the scientist and the literature, studying a myriad of theories. The theoretical coding polymorphism of classic GTM is possible precisely because "GT does not have an epistemology with an attached theoretical perspective that provides one set of TCs [theoretical codes] to the exclusion of others" (Glaser, 2005 p.17).

The IS literature offers several instances where formal theories were used successfully as theoretical lenses to present a coherent view of the emerging substantive theories. For example, Levina's (2005) study of collaborative practices on information systems development (ISD) projects used Schön's (1983) concept of reflection-in-action to propose that multiparty collaborative practice can be cognized as constituting a "collective reflection-in-action." This concept transcends the specific substantive field to be applicable to other multi-party collaborative projects, beyond the scope of ISD practice from which the theory emerged.

Barrett and Walsham (1999) also provide a good example of how to seek and use theoretical codes in grounded theory studies. In this case, the researchers were well aware of the literature and the different, often contradictory, viewpoints regarding the role information and communication 
technology (ICT) plays in transforming work practices. Yet, they consciously remained flexible and open to emergence, and it was only after completing the first round of data analysis that the relevance (or fit) of a particular theoretical lens became apparent. The usefulness of Giddens's theory on social transformation (Giddens, 1990, Giddens, 1991) was not conceived a priori but rather "developed as part of an emergent process during periods of reflection between different stages of this intensive longitudinal research" (Barrett and Walsham, 1999 p.6). Further, the theoretical lens was found after analysing 36 interviews and intensively reviewing the literature for theories that would fit the data. As such it was a valuable tool to understand the role of ICT in transforming the work at the London Market (Barrett and Walsham, 1999). By using Giddens's social transformation theory as a theoretical code, the researchers extended the substantive grounded theory, increasing its generalisability to other cases in which work practices are substantially transformed by technology adoption. In addition, the study contributed to the extension of social transformation theory to consider the role of information technology in the transformation process.

While GTM can be and has been used to produce rich descriptions of high quality and value (i.e., Gopal and Prasad, 2000), using GTM for descriptive work stops short of achieving its full potentialthat is, producing theoretical conceptualisations that are well integrated with the extant theory. Our view on this issue is consistent with GTM literature: the conceptualisation level can be improved by the extra step of engaging formal theories to further explain and integrate the emerging substantive theory. While not mandatory, this step is an important component of the method that should be seriously considered in order to achieve the full potential of GTM.

\section{Misconception 4 - GTM Is Positivist/Interpretivist/Critical}

Grounded Theory has long been plagued with debates about its underlying philosophical position, a good example in IS being the Bryant (2002) and Urquhart (2002) debate about the inherently positivistic nature of grounded theory method. In health research, Annells (1996) points to statements by Glaser (1992) about grounded theory focusing on 'concepts of reality'(p.14) and searching for 'true meaning'(p.55) as evidence of a critical realist position. In management research, Fendt and Sachs (2008) reject both the idea that theory is something neutral to be discovered in the data, and the idea that what is discovered is objective. However, the assumption that GTM is inherently positivist or interpretivist is not supported by the Straussian or Glaserian literature or by the extant GTM research literature.

Grounded theory was conceived as a general method with no explicit correct epistemology in which "all is data" is a key and consistent dictum (Glaser, 1978, Glaser, 1998, Glaser and Strauss, 1967). Thus, GTM as a research method is orthogonal not only to the type of data used; it can be appropriated by researchers with different assumptions about knowledge and how it can be obtained.

Hence, the assertion that GTM is positivist, interpretive, critical realist or constructivist is neither supported by the grounded theory literature, nor based on research practice. GTM is in many ways neutral and should be seen as a container into which any content can be poured (Charmaz, 2006 p.9). This level of epistemological neutrality makes GTM a highly useable research method.

The general nature of GTM is corroborated by the IS literature, where researchers with dissimilar epistemological stances successfully used grounded theory to attain valuable research outcomes. Orlikowski (1993) stated that the three characteristics of grounded theory-inductive, contextual and processual - fitted with an interpretive research orientation. This can be usefully contrasted with Levina and Ross (2003), which related their emergent findings to a positivistic theory of core competences and organisational design. However, Kirsch (2004) adopted a "scientific realism" or "soft positivist" approach (Madill et al., 2000).

More broadly, a qualitative method, depending on its underlying epistemology, can be positivist, interpretivist or critical (Klein and Myers, 1999, Klein and Myers, 2001, Myers, 1997, Orlikowski and Baroudi, 1991). Similarly, qualitative GTM "in use" is influenced by the different underlying 
epistemologies guiding the grounded theory studies. Thus, a good advice for grounded theorists can be found in Madill et al.(2000 p.17) "qualitative researchers have a responsibility to make their epistemological position clear, conduct their research in a manner consistent with that position, and present their findings in a way that allows them to be evaluated appropriately."

Finally, GTM embodies some practices which are useful for all qualitative researchers, regardless of philosophical position. The idea of overlapping data collection and analysis (Langley, 1999), where the emerging theoretical storyline directs successive data sampling, ensures a grounded approach to theory building even if GTM processes are not otherwise used. Similarly, the interplay between theorising and data categorisation in GTM is not dissimilar to the principle of dialogical reasoning in Klein and Myers (1999).

\section{Addressing the Misconceptions: Some Guidelines}

In this section, we advance three guidelines that help to navigate some of the misconceptions discussed above. These guidelines give practical advice to researchers when they feel that they are coming across barriers to GTM use, and are based in our long standing experience of many different GTM projects. The intention is for these to be working guidelines that are flexible, as is GTM.

\section{Guideline 1 - Use a phased literature review}

Glaser and Strauss (Glaser and Strauss, 1967 p.3) argue researchers should not approach reality as a tabula rasa, but must have $a$ theoretical perspective that will help them to abstract significant categories from the data. To define this perspective, a grounded theory investigation typically starts with a pre-study literature review to define the problem domain and the appropriate methodology for the study. Thus, the appropriate use of the literature in GTM can be seen as a question of phasing as shown in Figure 1 (Martin, 2006, McCallin, 2003). The first phase is noncommittal in which the researcher scans the literature to develop theoretical sensitivity and find the research problem and learns about the methodology. The second phase is integrative in which the researcher compares the emergent theory with extant theories to render the new theory in the context of existing knowledge and thus make the substantive theory more valuable.

\section{$<<$ Insert Fig 1 Here $>>$}

During the noncommittal phase, the GTM researcher conducts a preliminary literature review to (a) help develop theoretical sensitivity before conducting fieldwork and (b) understand the nature and the form of the enquiry. The preliminary literature review informs about existing theories, how other investigators may have addressed aspects of our research problem or attacked similar situations in other areas. The objective is not to develop a research question, as in other types of studies, but rather to define the scope for exploring a wider research problem. During this phase, potentially relevant literature should be noted for future comparison. This is done keeping in mind the key objective of generating theory that will engage with the literature based on relevance and fitness. In short, this review is conducted on the fundamental understanding that the generated grounded theory will determine the relevance of the literature, never the converse.

For novel grounded theorists, the preliminary literature review must involve reading the central works explaining the method and the philosophy of research behind GTM (McCallin, 2003). This work enables would-be GTM researchers to understand the methodology, the method and the coding techniques to be used. Strauss and Corbin (1990 p.4), define methodology as "a way of thinking about and studying social reality," method as "a set of procedures and techniques for gathering and analyzing data" and coding as "the analytic processes through which data are fractured, conceptualized, and integrated to form theory." Failing to study the methodology in sufficient detail raises significantly the risk of doing a bad grounded theory study - that is, a study in which the emergence process is jeopardised, reaching saturation is difficult, and the result shows poor conceptual densification or inadequate integration with extant theories. It also raises the risk of mislabelling(Jones and Noble, 2007). 
During the integrative phase we suggest that two types of literature reviews are conducted: thematic and theoretical. Once the empirical study is underway and the theoretical concepts start to emerge, the researcher returns to the extant literature to help develop the emerging concepts. This is called thematic literature review. The primary concern at this stage is to seek converging and diverging literature to compare against observed patterns and emerging theoretical conceptualisations. In this sense, the literature is treated as theoretical data that enrich the study.

It is likely that, while comparing emerging patterns or concepts against the literature, researchers will realise the need for further theoretical sampling, to progress toward saturation. Thus, the thematic review is a very important activity with a substantial role to play in the advancement of the study and also in the quality of the emerging conceptualisations, which become more robust and well-informed. This is also an intellectually stimulating process, as the researcher generates new ideas and theoretical memos, thanks to the exposure to the literature and its comparison against the substantive data. It should be noted that the role of theoretical memos is fundamental in theoretical emergence (Glaser, 1978, Glaser, 1998, Glaser and Strauss, 1967).

Also during the integrative phase, the theoretical review becomes important. That is, once the core pattern has been defined, it is important to seek its integration with relevant theories before the theorist finally formulates a grounded theory. This integration relates the phenomenon observed in the substantive field to the wider literature in that same or a related field. By doing so, both the value of the proposed grounded study and its publication opportunities are enhanced.

An example from IS of this process of engaging with the literature can be found in Orlikowski's (1996) study of transformation of work practices and organisational structures. The study's central concern was to observe and learn from the actions of the participants via the analysis of rich empirical data from interviews, observations and documents. By letting the empirical evidence guide the study, Orlikowski was able to understand what was going on in the studied field.

Orlikowski (1996) shows how to use the data analysis process to guide conceptual emergence and to engage with the extant literature. Starting from a suitable question (an exploration of how actors were dealing with a particular problem), Orlikowski studied the substantive field to identify issues and topics, and to detect patterns. The data analysis provided Orlikowski with the fundamental knowledge to incorporate relevant thematic literature. In this study, the extant literature was used to increase theoretical sensitivity (being able to understand the observations in a wider theoretical context) and to enrich and integrate the emerging conceptualisations. By integrating emerging concepts and patterns with the literature, Orlikowski (1996) presented a valuable, well-informed, substantive theory that advanced our knowledge on organisational transformation, changing long-held perspectives on planned change, technological imperative and punctuated equilibrium. This research outcome was achieved by following an effective interpretation of the canons of the method, which included a successful theoretical integration with the extant literature.

\section{Guideline 2 - Use GTM flexibly but knowledgeably}

Given that GTM in use can be flexible, how should IS researchers new to GTM maximise their chances of using GTM in a manner that suits their research objectives? We propose the following three action points:

1. Since GTM is more than a collection of techniques, it is critical to become acquainted first with Glaser and Strauss (1967) and then to read as much of the grounded theory method as possible before proceeding to data collection (see Table 1). While reading the central books is essential during the preliminary phase of the study, researchers are certain to return to these texts seeking further understanding of the method (Ekstrom, 2006). This is simply good scholarship and can be described as understanding the intellectual tradition of GTM. It is also very practical adviceknowing the roadmap, as it was set by the originators of GTM, facilitates the research process, 
contributes to avoiding unnecessary confusion, enables conceptual emergence, and improves research outcome.

\section{$<<$ Insert Table 1 Here $>>$}

2. The use of GTM in the IS literature shows that research value can be achieved in different ways. Thus, we advise IS researchers to be clear about the purpose for which they are using GTM-to leverage the strength of very well defined coding procedures for the purposes of data analysis, or for the purposes of building theory.

3. Undeniably, the alignment of research objectives, philosophical position, skills, data and methods is as important in GTM as it is to any other form of research. Researchers should carefully appraise their skills against the multiple demands of the method. Chapter 15 of Glaser (1998) provides suitable ideas as to how to develop the necessary knowledge and skills, while chapter two of Glaser (1978) provides a clear analysis of the demands imposed by the method.

\section{Guideline 3 - When Writing Up the GTM Article, Consider Exemplars in our field}

The cycle of a GTM study is completed when the theorist can add to the current literature; once the theory has been generated from the data through constant comparison and integration (Martin, 2006). Thus, considering how to present literature in a GTM article, and how a GTM article should be presented, are non-trivial issues for authors.

Clearly, there are tensions between the way grounded theorists work with the literature while doing the research and the way the literature is traditionally presented in journal articles. On the one hand, if the literature is discussed first, as is common with other methods, authors may feel that they are not truly representing the manner in which the literature was incorporated into the study. On the other hand, if the literature is presented later, the reader may not have the necessary information to appropriately follow and evaluate the argument. Suddaby (2006) provides a reasonable solution to this dilemma: "authors can note that, although they are presenting theoretical concepts in a traditional manner (i.e., up front in the study), the concepts did, in fact, emerge from the study."

Several articles in the IS literature can serve as exemplars to those researchers aiming their papers at top-tier journals. This section is not intended to cover all these papers, but rather to present a few exemplars covering different types of application of grounded theory, as published in top IS journals. We first present a case of a full use of GTM (Barrett and Walsham, 1999); then a case of a full GTM study without adopting a single theoretical lens (Garud and Kumaraswamy, 2005); followed by a case in which a particular technique suitable for the method is explained (Hunter and Beck, 2000); and finally a case of partial use of GTM without incurring mislabelling (Montealegre and Keil, 2000).

The Barrett and Walsham (1999) article on electronic trading and work transformation in the London insurance market, provides an excellent example of how to conduct and report GTM in a manner that is both comprehensive and easy to read and follow. The treatment of the literature during the study follows a grounded theory approach. Theoretical sensitivity was present and acknowledged (i.e., IT and transformation literature). Emerging data was sorted into themes, and these were analysed without a preconceived coding scheme, and then integrated with the extant literature. The grounded themes guided theoretical sampling during this intensive longitudinal exploration. Finally, the substantive theory was integrated with a Giddens (1991) theory on social transformation.

The core purpose of Barrett and Walsham (1999) was to present the conceptual scheme emerging from their study. The genius of the article is that while presenting the study to the reader in a traditional form, it also provides readers with a good appreciation of the sequence in which the theory was developed. The process is made explicit "The approach taken in research did not follow a topdown method where a conceptual scheme was developed and the fieldwork then conducted to confirm its value" (p.6). The authors explained the research activities in sufficient detail, and readers of the article are informed about what they did, how they did it and why they did it during their research. Yet, the paper remained focused on the core objective of explaining the emerging conceptual scheme. 
Another excellent example of research that followed the principles of GTM can be found in Garud and Kumaraswamy (2005). The paper reports a longitudinal study in which the authors engaged in a systematic exploration process of theoretical sampling, inductive data analysis and development of grounded theory, in order to generalise from case to theory (following the approach outlined in Lincoln and Guba, 1985). This article shows how to integrate the literature and how to explain the research process the data analysed (interviews, ethnographic observations, reports, presentations, white papers and employee surveys). The paper also shows how a rich case description can be used to inform and situate the reader, before presenting the conceptualisation of the studied process.

The explanation of the use of GTM can be extensive or brief, depending on the nature of the article. Hunter and Beck's (2000) article on the use of repertory grids within a grounded theory method focused on describing how a particular technique, the role construct repertory test (RepGrid) developed by psychologist George Kelly. Thus, the paper spends little time on grounded theory itself, but a substantial effort was devoted to explaining how and why the proposed technique can be used to elicit information during qualitative interviews of experts in cross-cultural studies.

It should also be noted that GTM is not always the driving paradigm. Some studies only apply GTM techniques and principles to data analysis, without getting involved in theoretical sampling and often with the purpose of generating rich descriptions. In such cases, the study cannot claim to be GTM without incurring mislabelling. In these cases, Montealegre and Keil (2000) serve as an example of correct methodological labelling, as they do not claim that their study is GTM, but rather it is appropriately labelled as a case study that uses GTM data analysis techniques. These authors present their research procedures in detail in an appendix, allowing the reader to be informed about an important aspect of their approach, without getting distracted from the main argument.

\section{Discussion}

One motivation for writing this paper is that we were aware that GTM remains a contested concept in IS (Bryant and Charmaz, 2007). We have shown that there are important misunderstandings about GTM in IS (Suddaby, 2006, Urquhart and Fernandez, 2006) and that a more scholarly approach to GTM can serve to further the use of the methodology. In doing so we add to the plurality of IS research methods available to IS researchers (Lee, 2010, Taylor et al., 2010).

When discussing the contested nature of GTM in general, Bryant and Charmaz (2007) argue that GTM has high recognition value, and claims for its use provide partial validation of a researcher's study. This methodological accreditation is one of the causes of 'mislabelled' grounded theory, where the label 'GTM' becomes a convenient description of any coding method, and confers respectability on that method because of the recognition value of GTM. Certainly there are many cases of mislabelling in IS, including instances of mislabelling where the role of grounded theory method is downplayed for reasons of the review process - this also reveals the contested nature of GTM in IS.

An internally complex character is also a feature of a contested concept, and the fact that GTM has a long and complex intellectual history pays tribute to that character. The complexity of GTM, coupled with its surface simplicity, makes it subject to misconceptions. The complexity is manifested in the delayed effect which characterises the method (Glaser, 1978, Glaser, 1998). In IS, this internally complex character is no less obvious than in any discipline - we too have many different interpretations of GTM in evidence.

Contested concepts also have a variety of descriptions. This is well illustrated by how GTM has evolved into either Glaserian or Straussian versions, and other characterisations such as Charmaz (2006). In IS, this is evident in the different descriptions of the method (Orlikowski, 1993, Walsham, 1995) and also in debates on epistemological origins of GTM (Bryant, 2002, Urquhart, 2002).

The final aspect of a contested concept is that it must be able to admit unpredictable modifications in the light of circumstances. We see different applications and adaptation of GTM in IS research, 
including its use with: cases studies, both as the overarching method and as a subservient coding technique (Barrett and Walsham, 1999, Kaplan and Duchon, 1988, Levina and Ross, 2003, Webster, 1998); action research (Baskerville and Pries-Heje, 1999); phenomenology and hermeneutics (Trauth and Jessup, 2000); ethnography (Levina, 2005); surveys (Feller et al., 2008, Ransbotham and Mitra, 2009); and, within a symbolic interaction methodological framework (Gopal and Prasad, 2000). As more IS researchers use GTM, we would call on those researchers to reflect on those adaptations, rather than perceiving their use as a deviation from 'pure' GTM.

Gallie's criteria also state that the continuous competition for acknowledgement should allow for "the original exemplar's achievement to be sustained and/or developed in optimum fashion". For GTM in general, there can be no doubt that the exemplar is the Discovery of Grounded Theory. For IS specifically, it can be argued that Orlikowski (1993), represents an early exemplar, and that others have followed and developed the application of the method in IS. Our view is that, despite the notable exceptions that we have used as exemplars, GTM in IS research has not yet reached the optimum situation described by Gallie. An optimum situation would be where there are many examples of GTM being applied in high level journals in IS.

Therefore, GTM in IS has the characteristics of an essentially contested concept. This is not surprising (Bryant and Charmaz, 2007). But, in this paper we have demonstrated how this contested nature of GTM as a concept is cause for misinterpretations and misrepresentations.

The core message of this article is that GTM has a deceptive simplicity, which can induce the illusion that competence is possible without incurring in the necessary scholarly effort. In our view, the most damaging misconception is the researcher as a blank slate - nothing could be further from the truth in grounded theory. We believe that when the literature is addressed as intended by the method, including a deep study of the GTM literature during the noncommittal phase of the study, the likelihood of incurring further misconceptions is greatly reduced, if not eliminated. Our suggested guidelines provide some flexible advice not only about the use of literature in the early stages, but also the much needed theoretical integration of the substantive theories produced by GTM, as seen in some of the existing exemplars in our discipline.

\section{Conclusion}

This paper is written to support and inform those people who wish to use GTM. As such it is useful for experienced academics, theorists new to GTM, and anyone curious about the potential of GTM as a rigorous and relevant method for IS research. Most of the misunderstandings we discussed tend to, intentionally or unintentionally, legitimise the view that GTM is an impractical research method, particularly for dissertation research. This has not been our experience, nor is it founded on evidence. The GTM has certain advantages, such as: relevance, as it has a built-in closeness to the data; rigor, in the form of clearly prescribed analysis procedures; and a clear pathway to generating substantive theories. It is also a flexible research method that is suitable for researching socio-technical processes and for building theory in unexplored areas - two strengths that could undoubtedly benefit IS research.

Future questions about the use of GTM include the consideration of whether, because of the unique nexus between people and technology in IS, this necessitates adaptations of GTM, and what type of adaptations they might be.

Finally, we turn to the question concerning the potential of GTM for theory building in IS, given that theory-building has been identified as a key requirement for the further development of the IS field (Baskerville and Myers, 2002, Markus and Saunders, 2007). A more nuanced and reflective use of GTM should contribute to building rigorous IS theories, that are based in practice, and effectively engaged with the relevant literature. Such a use would enhance the potential of grounded theory to make a much bigger contribution to IS research. 


\section{References}

Alvesson, M. and Sköldberg, K. 2000. Reflexive methodology : new vistas for qualitative research, London ; Thousand Oaks, Calif., SAGE.

Andrew, T. 2006. The Literature Review in Grounded Theory: A Response to McCallin (2003). The Grounded Theory Review: an international journal, 5, 29-41.

Annells, M. P. 1996. Grounded Theory Method: Philosophical Perspectives, Paradigm of Inquiry, and Postmodernism. Qualitative Health Research, 6, 379-393.

Barrett, M. and Walsham, G. 1999. Electronic trading and work transformation in the London Insurance Market. Information Systems Research, 10, 1-22.

Baskerville, R. and Pries-Heje, J. 1999. Grounded action research: a method for understanding IT in practice. Accounting, Management and Information Technologies, 9, 1-23.

Baskerville, R. L. and Myers, M. D. 2002. Information Systems as a Reference Discipline. MIS Quarterly, 26, 1-14.

Becker, P. H. 1993. Common pitfalls in published grounded theory research. Qualitative Health Research, 3, 254-260.

Benoliel, J. Q. 1996. Grounded Theory and Nursing Knowledge. Qualitative Health Research, 6, 406-428.

Bryant, A. 2002. Re-grounding Grounded Theory Journal of Information Technology Theory and Application, $4,25-42$.

Bryant, A. and Charmaz, K. (eds.) 2007. The SAGE Handbook of Grounded Theory, London, UK, Thousand Oaks, CA, USA: SAGE Publications.

Calloway, L. J. and Ariav, G. Year. Developing and Using a Qualitative Methodology to Study Relationships Among Designers and Tools. In: Nissen, H. E., Klein, H. \& Hirschheim, R., eds. Proceedings of the IFIP WG 8.2 Working Conference, 14-16 December 1991 Copenhagen, DK. Amsterdam, North-Holland, 175193.

Carlson, P. J. and Davis, G. B. 1998. An Investigation of Media Selection among Directors and Managers: From "Self" to "Other" Orientation. MIS Quarterly, 22, 335-362.

Charmaz, K. 2006. Constructing Grounded Theory: A Practical Guide through Qualitative Analysis, Thousand Oaks, CA, USA, SAGE Publications.

Corbin, J. M. and Strauss, A. L. 2008. Basics of qualitative research : techniques and procedures for developing grounded theory, Los Angeles, SAGE Publications.

Eisenhardt, K. M. 1989. Building Theories from Case Study Research. Academy of Management Review, 14, 532-550.

Ekstrom, H. 2006. Aspects on McCallin's paper, "Grappling with the literature in a grounded theory study"? The Grounded Theory Review: an international journal, 5, 45-47.

Elliott, N. and Lazenbatt, A. 2005. How to recognise a 'quality' grounded theory research study. Australian Journal of Advanced Nursing, 22, 48-52.

Feller, J., Finnegan, P., Fitzgerald, B. and Hayes, J. 2008. From Peer Production to Productization: A Study of Socially Enabled Business Exchanges in Open Source Service Networks Information Systems Research, $19,475-493$.

Fendt, J. and Sachs, W. 2008. Grounded Theory Method in management research: Users' perspectives. Organizational Research Methods, 11, 430-455.

Fernandez, W. D. and Lehmann, H. P. 2005. Achieving Rigour and Relevance in Information Systems Studies: Using grounded theory to investigate organizational cases. The Grounded Theory Review: an international journal, 5, 79-107.

Galal, G. 2001. From contexts to constructs: the use of grounded theory in operationalising contingent process models. European Journal of Information Systems, 10, 2-14.

Gallie, W. B. Year. Essentially Contested Concepts. In: Proceedings of the Aristotelian Society, 1956. Blackwell Publishing, 167-198. 
Garud, R. and Kumaraswamy, A. 2005. Vicious and Virtuos Circles in the Management of Knowledge: The Case of Infosys Technologies. MIS Quarterly, 29, 9-33.

Giddens, A. 1990. The consequences of modernity, Stanford, Calif., Stanford University Press.

Giddens, A. 1991. Modernity and self-identity : self and society in the late modern age, Stanford, Calif., Stanford University Press.

Glaser, B. G. 1978. Theoretical Sensitivity: Advances in the methodology of grounded theory, Mill Valley, Calif, Sociology Press.

Glaser, B. G. 1992. Emergence vs. Forcing: Basics of Grounded Theory Analysis, Mill Valley, CA, Sociology Press.

Glaser, B. G. 1998. Doing Grounded Theory: Issues and Discussions, Mill Valley, Calif, Sociology Press.

Glaser, B. G. 2001. The Grounded Theory Perspective: Conceptualization Contrasted with Description, Mill Valley, Calif, Sociology Press.

Glaser, B. G. 2005. The Grounded Theory Perspective III: Theoretical Coding, Mill Valley, Calif, Sociology Press.

Glaser, B. G. 2007. Doing Formal Grounded Theory: A Proposal, Mill Valley, Calif, Sociology Press.

Glaser, B. G. 2009. Jargonizing: Using the Grounded Theory Vocabulary, Mill Valley, CA, USA, Sociology Press.

Glaser, B. G. and Strauss, A. L. 1965. Awareness of Dying, New York, Aldine Publishing Company.

Glaser, B. G. and Strauss, A. L. 1967. The discovery of grounded theory: Strategies for qualitative research, New York, Aldine Publishing Company.

Gopal, A. and Prasad, P. 2000. Understanding GDSS in Symbolic Context: Shifting the Focus from Technology to Interaction. MIS Quarterly, 24, 509-546.

Green, J. 1998. Grounded theory and the constant comparative method. British Medical Journal, 316, 1064 1065.

Hunter, M. G. and Beck, J. E. 2000. Using Repertory Grids to Conduct Cross-Cultural Information Systems Research. Information Systems Research, 11, 93-101.

Jones, R. and Noble, G. 2007. Grounded theory and management research: a lack of integrity? Qualitative Research in Organizations and Management: An International Journal, 2, 84-103.

Kaplan, B. and Duchon, D. 1988. Combining Qualitative and Quantitative Methods in Information Systems Research: A Case Study. MIS Quarterly, 12, 571-586.

Kirsch, L. J. 2004. Deploying Common Systems Globally: The Dynamics of Control. Information Systems Research, 15, 374-396.

Klein, H. K. and Myers, M. D. 1999. A Set of Principles for Conducting and Evaluating Interpretive Field Studies in Information Systems. MIS Quarterly, 23, 67-93.

Klein, H. K. and Myers, M. D. 2001. A Classification Scheme for Interpretive Research in Information Systems. In: Trauth, E. M. (ed.) Qualitative Research in IS: Issues and Trends. Hershey, PA: Idea Group Publishing.

Lamb, R. and Kling, R. 2003. Reconceptualizing Users as Social Actors in Information Systems Research. MIS Quarterly, 27, 197-236.

Langley, A. 1999. Strategies for theorizing from process data. Academy of Management Review, 24 691-710.

Layder, D. 1993. New Strategies in Social Research: an introduction and guide, Cambridge, UK, Polity Press.

Lee, A. S. 2010. Retrospect and prospect: information systems research in the last and next 25 years. Journal of Information and Technology, 25, 336-348.

Levina, N. 2005. Collaborating on Multiparty Information Systems Development Projects: A Collective Reflection-in-Action View. Information Systems Research, 16, 109-133.

Levina, N. and Ross, J. W. 2003. From the Vendor Perspective: Exploring the value proposition in information technology outsourcing. MIS Quarterly, 27, 331-364. 
Levina, N. and Vaast, E. 2005. The Emergence of Boundary Spanning Competence in Practice: Implications for Implementation and Use of Information Systems. MIS Quarterly, 29, 335-363.

Levina, N. and Vaast, E. 2008. Innovating or Doing as Told? Status Differences and Overlapping Boundaries in Offshore Collaboration, . MIS Quarterly, 32, 307-332.

Lincoln, Y. S. and Guba, E. G. 1985. Naturalistic inquiry, Beverly Hills, CA, USA, SAGE Publications.

Lings, B. and Lundell, B. 2005. On the Adaptation of Grounded Theory Procedures: Insights from the Evolution of the $2 \mathrm{G}$ Method. Information Technology and People, 18, 196-211.

Madill, A., Jordan, A. and Shirley, C. 2000. Objectivity and reliability in qualitative analysis: Realist, contextualist and radical constructionist epistemologies. British Journal of Psychology, 91, 1-20.

Markus, M. L. 1997. The Qualitative Difference in Information System Research and Practice. In: DeGross, J. I., Liebenau, J. \& Lee, A. S. (eds.) Information systems and qualitative research. London: Chapman \& Hall.

Markus, M. L. and Saunders, C. 2007. Looking for a Few Good Concepts... and Theories...for the Information Systems Field. MIS Quarterly, 31.

Martin, P. Y. and Turner, B. A. 1986. Grounded Theory and Organizational Research. The Journal of Applied Behavioral Science, 22, 141-157.

Martin, V. B. 2006. The Postmoderm Turn: Shall Classic Grounded Theory Take That Detour? A review Essay. The Grounded Theory Review: an international journal, 5, 119-129.

McCallin, A. M. 2003. Grappling with the Literature in a Grounded Theory Study. Contemporary Nurse, 15, 62-69.

Montealegre, R. and Keil, M. 2000. De-Escalating Information Technology Projects: Lessons from the Denver International Airport. MIS Quarterly, 24, 417-447.

Myers, M. D. 1997. Qualitative Research in Information Systems. MIS Quarterly, 21, 241-242.

Myo. 2012. Grounded Theory: "Whenever possible, stay away from it" "It is too complicated, and difficult to handle and manage.". http://whatihavelearntrecently.blogspot.co.uk [Online]. [Accessed 26/4/1012].

Orlikowski, W. J. 1993. CASE Tools as Organizational Change: Investigating Incremental and Radical Changes in Systems Development. MIS Quarterly, 17, 309-340.

Orlikowski, W. J. 1996. Improvising organizational transformation over time: A situated change perspective. Information Systems Research, 7, 63-103.

Orlikowski, W. J. and Baroudi, J. J. 1991. Studying Information Technology in Organizations: Research Approaches and Assumptions. Information Systems Research, 2, 1-28.

Ransbotham, S. and Mitra, S. 2009. Choice and Chance: A Conceptual Model of Paths to Information Security Compromise. Information Systems Research, 20, 121-139.

Schön, D. A. 1983. The Reflective Practitioner: How Professionals Think in Action, New York, Basic Books.

Stern, P. N. 1994. Eroding Grounded Theory. In: Morse, J. (ed.) Critical Issues in Qualitative Research Methods. Thousand Oaks, CA: Sage Publications.

Strauss, A. L. 1987. Qualitative analysis for social scientists, Cambridge, Cambridge University Press.

Strauss, A. L. and Corbin, J. M. 1990. Basics of qualitative research: grounded theory procedures and techniques, Newbury Park, Calif, Sage Publications.

Suddaby, R. 2006. From the Editors: What Grounded Theory is Not. Academy of Management Journal, 49, 633-642.

Taylor, H., Dillon, S. and Van Wingen, M. 2010. Focus and Diversity in IS Research: Meeting the dual demands of a healthy applied discipline. MIS Quarterly, 34, 647-667.

Toraskar, K. Year. How Managerial Users Evaluate Their Decision Support: a Grounded Theory Approach. In: Nissen, H. E., Klein, H. \& Hirschheim, R., eds. Proceedings of the IFIP WG 8.2 Working Conference, 14-16 December 1991 Copenhagen, DK. Amsterdam, North-Holland, 195-225.

Trauth, E. M. and Jessup, L. M. 2000. Understanding Computer-Mediated Discussions: Positivist and Interpretive Analyses of Group Support System Use. MIS Quarterly, 24, 43-79. 
Urquhart, C. 2002. Regrounding Grounded Theory - Or Reinforcing Old Prejudices? A Brief Reply to Bryant. Journal of Information Technology Theory and Application, Vol 4, 43-54.

Urquhart, C. and Fernandez, W. D. Year. Grounded Theory Method: The Researcher as Blank Slate and Other Myths. In: The International Conference on Information Systems, 2006 Milwaukee, WI, USA.

Urquhart, C., Lehmann, H. and Myers, M. 2010. Putting the Theory Back into Grounded Theory: Guidelines for Grounded Theory Studies in Information Systems. Information Systems Journal, 20, 357-381.

Urquhart, C., Lehmann, H. and Myers, M. D. 2009. Putting the theory back into grounded theory: guidelines for grounded theory studies in information systems. Information Systems Journal, 20, 357-381.

Van de Ven, A. H. and Poole, M. S. 1989. Methods for studying innovation processes. In: Van de Ven, A. H., Angle, H. L. \& Poole, M. S. (eds.) Research on the Management of Innovation: The Minnesota Studies. New York: Harper \& Row.

Vannoy, S. A. and Salam, A. F. 2010. Managerial Interpretations of the Role of Information Systems in Competitive Actions and Firm Performance: A Grounded Theory Investigation. Information Systems Research, 21, 496-515.

Walsham, G. 1995. Interpretive case studies in IS research: nature and method. European Journal of Information Systems, 4, 74-81.

Webster, J. 1998. Desktop Videoconferencing: Experiences of Complete Users, Wary Users, and Non-Users. MIS Quarterly, 22, 257-286.

\section{About the Authors}

Cathy Urquhart is Professor of Digital and Sustainable Enterprise at Manchester Metropolitan University Business School. She is a past Senior Editor for MIS Quarterly and an Associate Editor for Information Technology and Development. Honours and awards include; Best paper award, Pan Pacific Conference on Information Systems (PACIS), AIS Volunteer Spotlight for Outstanding Contributions to Membership Services in 2008, MIS Quarterly Most Developmental Associate Editor in 2007, Outstanding Paper Award in the journal Information Technology and People in 2000. Her current research interests span Green IT, IT in developing countries, and social media. She has a strong interest in the use of grounded theory in information systems, and recently published her book Grounded Theory for Qualitative Research with Sage. Her website can be found here http://www2.business.mmu.ac.uk/staff/staffdetails.php?uref=430

Walter Fernandez is an Associate Professor and Co-Director of the National Centre for Information Systems Research at the Australian National University. Dr Fernandez's research focuses on the execution of major projects and programmes. He is interested on the execution of projects and programmes aiming at organizational change, modernization, or ICT for Development. Walter has published in journals such as Journal of Strategic Information Systems (JSIS), Journal of Organizational Computing and Electronic Commerce (JOCEC), European Journal of Information Systems (EJIS), Decision Support Systems (DSS), and the Australasian Journal of Information Systems (AJIS), The Grounded Theory Review (GTR) and Journal of Information Technology Case and Application Research (JITCAR). Dr Fernandez is the Inaugural Chair of the Association of Information Systems Special Interest Group on Grounded Theory Methodology (SIGGTM) and a Charter Member of the AIS Special Interest Group for Information Technology Project Management. $\mathrm{He}$ is also a member of the AIS Special Interest Group for Global Development and of the IFIP 8.2 Working Group on Information Systems and Organizations. Walter currently serves on the editorial boards of EJIS, GTR, JITCAR and AJIS. Walter is an expert user and scholar on the grounded theory method, and has delivered GTM seminars and workshops in more than ten countries in Australasia, Europe, Asia and North America. 


\section{Appendix}

<<Insert Table 2 Here>> 


\section{Figures and tables}

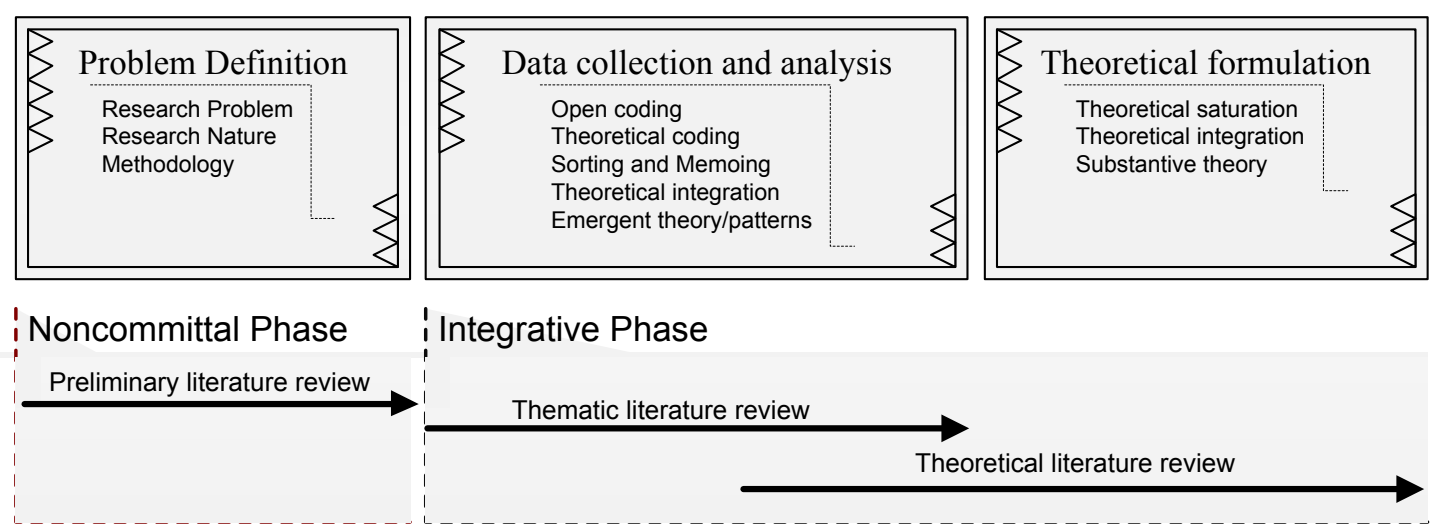

Figure 1: Key GTM activities and the continuous role of the literature review. 
Table 1: Central GTM books.

\begin{tabular}{|c|c|}
\hline 1. Book & Description \\
\hline $\begin{array}{c}\text { Glaser, B.G., and Strauss, A.L. } \\
\text { (1967) The discovery of grounded } \\
\text { theory: Strategies for qualitative } \\
\text { research. }\end{array}$ & $\begin{array}{c}\text { Provides a good understanding of GTM historical background, its research } \\
\text { philosophy and processes. Explains the key role of constant comparison. This } \\
\text { book is fundamental reading for any grounded theorist. }\end{array}$ \\
\hline $\begin{array}{c}\text { Glaser, B.G. (1978) Theoretical } \\
\text { Sensitivity. }\end{array}$ & $\begin{array}{c}\text { Covers important aspects of theoretical sensitivity, pacing, sampling, coding, } \\
\text { memos, sorting and writing, and provides a very important discussion on basic } \\
\text { social processes. Introduces the idea of theoretical coding. }\end{array}$ \\
\hline $\begin{array}{c}\text { Strauss, A.L. (1987) Qualitative } \\
\text { analysis for social scientists. }\end{array}$ & $\begin{array}{c}\text { Provides advice for the first time user of GTM, especially around relating } \\
\text { efforts to the technical literature, and the process of coding in a group. }\end{array}$ \\
\hline $\begin{array}{c}\text { Strauss, A.L. and Corbin J.M. } \\
\text { (1990). Basics of qualitative } \\
\text { research: grounded theory } \\
\text { procedures and techniques. }\end{array}$ & $\begin{array}{c}\text { A widely read yet controversial book because of its rendering of GTM. Gives } \\
\text { very clear procedures for GTM, but at the same time offers a narrower view of } \\
\text { the method. }\end{array}$ \\
\hline $\begin{array}{c}\text { Glaser, B. G. (1992). Emergence } \\
\text { vs. Forcing: Basics of Grounded } \\
\text { Theory Analysis. }\end{array}$ & $\begin{array}{c}\text { This book is the response to Strauss and Corbin (1990). Helps to understand the } \\
\text { divergent views held by Glaser and by Strauss and Corbin. It discusses in detail } \\
\text { the significance of the issue of 'forcing' in GTM. Yet, reading this book } \\
\text { without a good understanding of previous texts can obscure more than } \\
\text { illuminate. }\end{array}$ \\
$\begin{array}{c}\text { Glaser, B.G (1998) Doing } \\
\text { Grounded Theory: Issues and } \\
\text { Discussions }\end{array}$ & $\begin{array}{c}\text { This key book discusses practical aspects of the method, including: reading the } \\
\text { literature, forcing, generating concepts, theoretical sampling, theoretical coding, } \\
\text { memoing, sorting, and writing. }\end{array}$ \\
\hline $\begin{array}{c}\text { Glaser, B.G (2005) Grounded } \\
\text { Theory Perspective III: } \\
\text { Theoretical Coding }\end{array}$ & $\begin{array}{c}\text { This book broke new ground in thinking about theoretical coding and the } \\
\text { process of relating categories. It introduced 23 new 'coding families' to } \\
\text { complement the original 18 coding families in the 1978 book }\end{array}$ \\
\hline
\end{tabular}


Table 2: Examples of GTM use in IS research.

\begin{tabular}{|c|c|c|}
\hline Study & Jour. & How GTM was used \\
\hline $\begin{array}{l}\text { Kaplan and } \\
\text { Duchon }(1988)\end{array}$ & MISQ & $\begin{array}{l}\text { To study relationships between a computer system and the perceptions of its users. GTM used in } \\
\text { a mixed method approach to case study research. }\end{array}$ \\
\hline $\begin{array}{l}\text { Orlikowski } \\
\quad(1993)\end{array}$ & MISQ & $\begin{array}{l}\text { Classic GTM used to produce a theoretical model of strategic conduct in adopting and using } \\
\text { CASE tools in organizations. Engaged with formal innovation theory. }\end{array}$ \\
\hline $\begin{array}{l}\text { Carlson and } \\
\text { Davis (1998) }\end{array}$ & MISQ & $\begin{array}{l}\text { To study the media selection behavior of executives and managers. GTM (Glaser and Strauss, } \\
\text { 1967, Strauss, 1987) was used to guide data analysis. Cluster analysis technique (SPSS) was } \\
\text { used. Engaged with multiple theories of media selection. }\end{array}$ \\
\hline Webster (1998) & MISQ & $\begin{array}{c}\text { To study the use of desktop video conferencing. Classic GTM used to develop theory from a } \\
\text { longitudinal case study (Eisenhardt, 1989). Engaged with communication media choice, systems } \\
\text { analysis and design, and privacy. }\end{array}$ \\
\hline $\begin{array}{l}\text { Barrett and } \\
\text { Walsham } \\
(1999)\end{array}$ & ISR & $\begin{array}{l}\text { To study the role of IT in organizational transformation. Pseudo-Straussian GTM used to study a } \\
\text { single case. Engaged with and extended Giddens theory on social transformation. }\end{array}$ \\
\hline $\begin{array}{c}\text { Gopal and } \\
\text { Prasad }(2000)\end{array}$ & MISQ & $\begin{array}{l}\text { To study how group decision support systems (GDSS) were used in a university setting. Classic } \\
\text { GTM techniques used within a symbolic interaction methodological framework. The article } \\
\text { contributes rich descriptions from the field. }\end{array}$ \\
\hline $\begin{array}{l}\text { Hunter and } \\
\text { Beck }(2000)\end{array}$ & ISR & $\begin{array}{l}\text { To conduct cross-cultural research. Proposes the use of the RepGrid technique in GTM studies. } \\
\text { Describes how the technique is used to address emic vs. etic issues. }\end{array}$ \\
\hline $\begin{array}{c}\text { Trauth and } \\
\text { Jessup }(2000)\end{array}$ & MISQ & $\begin{array}{c}\text { To study computer-mediated discussions in group support systems (GSS).GTM (Glaser and } \\
\text { Strauss, 1967, Strauss, 1987) used for the interpretive part of a study that combined and } \\
\text { compared positivist and interpretive research. GTM was used in combination with ethnography } \\
\text { and hermeneutics. }\end{array}$ \\
\hline $\begin{array}{l}\text { Lamb and } \\
\text { Kling (2003) }\end{array}$ & MISQ & $\begin{array}{l}\text { To study ICT use and to develop an alternative to the user concept found in the literature. Classic } \\
\text { GTM used to develop a social actor model that can be used to conceptualize ICT research and } \\
\text { design. }\end{array}$ \\
\hline $\begin{array}{l}\text { Levina and } \\
\text { Ross }(2003)\end{array}$ & MISQ & $\begin{array}{l}\text { To study IT vendors value proposition in IT outsourcing. Classic GTM used with case study } \\
\text { data. Primarily engaged with Milgrom and Roberts' complementarity in organizational design } \\
\text { and with Hamel and Prahalad's core competency concept. }\end{array}$ \\
\hline Kirsch (2004) & ISR & $\begin{array}{l}\text { To study the dynamics of control during different phases of large IS projects. Used the } \\
\text { Straussian approach with case study (two cases) adopting a soft-positivist stance (Madill et al., } \\
\text { 2000). Engaged with the control literature. }\end{array}$ \\
\hline $\begin{array}{l}\text { Garud and } \\
\text { Kumaraswamy } \\
\quad(2005)\end{array}$ & MISQ & $\begin{array}{l}\text { To study challenges faced by organizations in harnessing knowledge. Classic GTM used to } \\
\text { analyze a data-rich longitudinal case study over a period of three years. Engaged with systems } \\
\text { theory. }\end{array}$ \\
\hline Levina(2005) & ISR & $\begin{array}{l}\text { To study multi-party collaborative practices in IS development projects. Classic GTM used in an } \\
\text { ethnographic study of IS development. Engaged with Schön's reflection-in-action theory. }\end{array}$ \\
\hline $\begin{array}{l}\text { Levina and } \\
\text { Vaast (2005) }\end{array}$ & MISQ & $\begin{array}{l}\text { To study the emergence of organizational competence in boundary spanning. GTM is used to } \\
\text { analyze data from case studies. Presents an excellent integration with the extant literature and } \\
\text { engages with Bourdieu's theory of practice. }\end{array}$ \\
\hline $\begin{array}{l}\text { Feller et } \\
\text { al.(2008) }\end{array}$ & ISR & $\begin{array}{l}\text { To study social mechanisms in open source service networks (OSSN). Straussian GTM used to } \\
\text { analyze data in a multi-method research guided by postpositivist epistemology. }\end{array}$ \\
\hline $\begin{array}{l}\text { Levina and } \\
\text { Vaast (2008) }\end{array}$ & MISQ & $\begin{array}{c}\text { To study offshore software development practices. Classic GTM used to build theory on } \\
\text { offshoring following an interpretive cases study approach(Walsham, 1995). Engaged with } \\
\text { Bourdieu's theory of practice. }\end{array}$ \\
\hline $\begin{array}{l}\text { Ransbotham } \\
\quad \text { and } \\
\text { Mitra(2009) }\end{array}$ & ISR & $\begin{array}{l}\text { To study information security. Classic GTM used to develop a conceptual model of paths to } \\
\text { information security compromise using observations, interviews, document reviews and } \\
\text { discussion groups. The model is empirically examined using alert data. }\end{array}$ \\
\hline $\begin{array}{l}\text { Vannoy and } \\
\text { Salam }(2010)\end{array}$ & ISR & $\begin{array}{l}\text { To study the utilization of IS in top managers' competitive actions. GTM (Corbin and Strauss, } \\
\text { 2008) used to produce a process model of IS, competitive action, and firm performance. The } \\
\text { relevant literature is engaged to discuss and present the model. }\end{array}$ \\
\hline
\end{tabular}


${ }^{i}$ See http://www.sociologypress.com/

ii The term 'formal' is used here in the sociological sense and should not be confused with other types of formality, such as those theories expressed in mathematical formal language. 